\title{
Couples' childbearing behaviour in Italy: which of the partners is leading it?
}

\author{
Maria Rita Testa, Laura Cavalli and Alessandro Rosina*
}

\begin{abstract}
Using data on 2356 Italian couples from the longitudinal survey on Family and Social Subjects conducted between 2003 and 2007, we examine the relationship between child-timing intentions and subsequent reproductive outcomes. Our hypothesis is that in Italy the lack of agreement between partners has an inhibiting effect on couple's pregnancy-seeking behaviour because inertia and social norms favour the partner who does not want to have a(nother) child. We find that this holds true only for couples who have already two or more children whereas at lower parities conflicting intentions result in either a middle fertility outcome or childbearing levels similar to those observed for couples who agree on having a child. Women have a greater influence on childbearing decisions than men. The explicit consideration of a partner's disagreement increases the predictive accuracy of fertility intentions. Our findings strongly support the adoption of a couple-oriented approach in fertility research.
\end{abstract}

\section{Introduction}

In his critical comments on the National American Fertility survey, Ryder (1973) emphasised the importance of considering the role of men in the analysis of fertility. Indeed the predominant approach even today assumes that women are inherently important for understanding reproductive behaviour, but they are not making their fertility choices unilaterally as childbearing decisions involve both men and women.

The contribution of men to the reproductive decision-making process has been under-investigated so far. One major difficulty in couple research lies in the need

\footnotetext{
* Maria Rita Testa (correspondence author), Vienna Institute of Demography, Austrian Academy of Sciences, Wittgenstein Centre for Demography and Global Human Capital.Wohllebengasse 12-14, 6th floor, 1040 Vienna, Austria. Email: maria.rita.testa@oeaw.ac.at Laura Cavalli, University of Lausanne, Switzerland.

Alessandro Rosina, Catholic University of Milan, Italy.
} 
to have high-quality data that collect information on both partners, possibly in repeated waves, allowing scholars to ascertain the differences between the partners' reproductive goals and disentangle the contribution of each partner to the final childbearing outcome.

If this is true for every country, the lack of adequate data affects even more those European countries where longitudinal household surveys were only seldom conducted in the last decades. Beyond the seminal article by Thomson and Hoem (1998) on Swedish couples' fertility there are not many papers addressing the issue of childbearing intentions and behaviour in Europe truly at a couple's level.

We aim to fill in this gap by examining fertility preferences and subsequent reproductive outcomes in a genuine couple's study. We use a longitudinal survey conducted by the Italian National Institute of Statistics between 2003 and 2007 to address the following research questions: What birth risks do couples in disagreement have? Which partner has the stronger influence on childbearing in case of conflicting intentions? Does the predictive accuracy of pregnancy intention improve if the partner's intentions are taken into account?

Our case study is Italy, a country characterised by a considerably high discrepancy between desired and actual fertility (Testa 2006), a predominance of traditional gender roles and a lack of work/family reconciliation policies (Saraceno 1994; Pinnelli 1995; Del Boca et al. 2004).

Our findings suggest that partners who were in disagreement about having a child show birth risks in between those of partners who both wanted a child and those of partners who both did not. Moreover, in case of a conflict the subsequent outcome tends to reflect more closely the woman's response than that of the man. Eventually, couples' fertility intentions predict the subsequent reproductive behaviour more accurately than individual intentions but women's responses are more reliable than men's responses if a choice between the two comes into play.

The rest of the article is organised as follows: first, we review the existing literature on couple's fertility intentions and behaviour, next, we present data and methodology and then we describe the main statistical findings. In the final section we discuss alternative interpretations of the results as well as possible caveats inherent to the analysis.

\section{What criteria underlie the resolution of partners' disagreement?}

Childbearing implies a joint couple decision but partners often have different fertility intentions at least at the beginning of their relationship. In case of disagreement they will try to reach a compromise by adjusting their initial childbearing plans. Since intentions may always change over time as moving targets (Lee 1980), such agreement will never be definitive till the end of the reproductive career. Our crucial question is what happens when the partners' 
preferences differ. In this section we review the existing relevant literature on the impact of partners' disparate intentions on the couple's subsequent reproductive behaviour. For the sake of simplicity we report in Table 1 the various principles which rule the resolution of a couple's disagreement as well as the effects on the childbearing outcomes.

Miller and Pasta (1996) introduced an important distinction between a so-called "absolute-difference effect", which mostly causes a delaying in childbearing independently on which spouse wants what, and a so-called "signeddifference effect", which depends on the decision rule at work within the couple, i.e. whether the woman or the man predominates.

The absolute-difference effect causes a delay in the birth of a child because of inertia (Davidson and Beach 1981). This mechanism favours the maintenance of the status quo that in low-fertility countries is likely to be the use of contraception between births. In such a context childbirth implies a couple's joint decision to stop contraception with the aim to seek pregnancy, hence, a preliminary explicit consensus of each of the partners. Several studies (Morgan 1985; Thomson et al. 1990; Thomson 1997; Thomson and Hoem 1998) have demonstrated that partners who disagree about childbearing plans have children at a later age than couples in which both partners share the intention to have a child. In some cases, a doubleveto model affects the resolution of a conflict: partners who have opposing plans experience a likelihood of childbearing only slightly higher than couples where both agree not to have a child (Miller and Pasta 1996; Thomson and Hoem 1998).

In the same vein, Voas (2003) emphasised that in the event of disparate intentions the varying degree of male and female influence over the subsequent fertility outcome depends on the prevalent social norms favouring one reproductive choice or the other, irrespective of which of the partners wants to have a child. He argued that in the low-fertility societies individuals attach greater importance to individual autonomy than to childbearing and therefore social forces tend to support someone who wishes to avoid having a child, and generally the partner's consent is expected before any attempt at conception.

The signed-difference effect impacts on the reproductive behaviour depending on which partner wants what (Miller and Pasta 1996). It is then extremely important to know the criteria underlying the resolution of couple disagreement in specific situations in which either she or he plans a child. A review of the existing literature highlighted three relevant aspects: the type of decision each partner wants to make, the level of gender equity, both at the individual and societal level, and the prevalent decision rule used by the partners to resolve conflicts.

Type of decision. Women prevail in positive fertility decisions and men predominate in negative childbearing plans. Townes et al. (1980), for example, argued that the wives' opinions are more important than the husbands' in determining whether couples will seek pregnancy, if wives are in favour of a pregnancy. Similarly, Beckman (1983) pointed out that in case of disagreement men predominate if the decision at stake is not to have a child while women 
prevail if the decision is to have a child. However, in a study on a sample of welleducated couples, Beckman (1984) found that in couples with discordant opinions wives are less likely to desire another child in the short run than husbands. Fried et al. (1980) and Beckman (1984) argued that wives may have a stronger influence than husbands over fertility decisions because contraceptive use and fertility are areas in which women have legitimate power in the marriage. In the same line, Rindfuss et al. (1988) showed that men's intentions are more easily adjustable to the preferences of their partner than women's intentions.

Table 1:

Synthesis of the elements relevant for the resolution of a couple's conflict

\begin{tabular}{|c|c|c|}
\hline Models & Description & Effects on fertility \\
\hline $\begin{array}{l}\text { Absolute-difference } \\
\text { model }\end{array}$ & $\begin{array}{l}\text { Partners have discrepant } \\
\text { fertility intentions }\end{array}$ & $\begin{array}{l}\text { Conflict effect. Delay of } \\
\text { birth, if contraception is the } \\
\text { standard regime }\end{array}$ \\
\hline Signed-difference model & $\begin{array}{l}\text { One partner has weaker or } \\
\text { stronger fertility intentions } \\
\text { than the other }\end{array}$ & $\begin{array}{l}\text { Influence effect. Likelihood } \\
\text { of a birth depends on which } \\
\text { of the partners has weaker or } \\
\text { stronger desires and the } \\
\text { decision rule at stake within } \\
\text { the couple }\end{array}$ \\
\hline Double-veto model & $\begin{array}{l}\text { Partners have discrepant } \\
\text { fertility intentions }\end{array}$ & $\begin{array}{l}\text { A birth is unlikely, as in } \\
\text { couples who agree not to } \\
\text { have a child }\end{array}$ \\
\hline \multicolumn{3}{|l|}{ DECISION RULES } \\
\hline Power & $\begin{array}{l}\text { Partner with more access to } \\
\text { economic resources (usually } \\
\text { the man) tends to prevail }\end{array}$ & $\begin{array}{l}\text { A birth occurs if the partner } \\
\text { with more access to } \\
\text { economic resources wants } \\
\text { to have a(nother) child }\end{array}$ \\
\hline Sphere of interest & $\begin{array}{l}\text { Partner in whose sphere of } \\
\text { interest childbearing lies } \\
\text { (usually the woman) tends } \\
\text { to prevail }\end{array}$ & $\begin{array}{l}\text { A birth occurs if the partner } \\
\text { in whose sphere of interest } \\
\text { childbearing lies wants to } \\
\text { have a(nother) child }\end{array}$ \\
\hline Social drift & $\begin{array}{l}\text { None of the partners has a } \\
\text { clear interest in changing } \\
\text { the status quo }\end{array}$ & A birth is postponed \\
\hline Golden mean & $\begin{array}{l}\text { Both partners have equal } \\
\text { power in the negotiations }\end{array}$ & $\begin{array}{l}\text { The occurrence of a birth } \\
\text { will depend on the final } \\
\text { outcome of the couple's } \\
\text { interaction }\end{array}$ \\
\hline
\end{tabular}

Gender equity. Men and women have equal influence over the subsequent childbearing outcome and neither the male or the female intention predominates (Miller and Pasta 1995), irrespective of whether the relationship is based on 
traditional or more equal gender roles (Thomson 1997; Thomson and Hoem 1998). However, in very traditional contexts in which women are still the main and perhaps the sole responsible of childrearing one might expect that men have less influence than women in the implementation of their fertility intentions especially if they live in a traditional union where the female partner does not work (Fried and Udry 1979; Coombs and Chang 1981). More generally, in contexts characterised by low gender equality men who equally share with their partner their household and family tasks may have a stronger fertility decisionmaking power than men who live in more traditional couples.

Decision rule. If the two partners differ in their child-number or child-timing intentions they try to reach a decision which could be mid-way between the preferences of either of the two (Thomson 1997; Thomson and Hoem 1998; Thomson et al. 1990; Jansen and Liefbroer 2006). The corresponding decision rule is called the golden-mean rule: partners view each other's intentions as equally important and since they have equal power in negotiation they will try to strike an acceptable compromise which then equally reflects their initial desires. Jansen and Liefbroer (2006) found that this is the most frequent heuristics approach used by couples in the Netherlands. They also discussed other possible decision rules which could be adopted by couples with disparate attitudes towards childbearing. The first one is the power rule according to which the partner who has the better access to socio-economic resources will prevail. As long as men have higher occupational and income levels than women they will predominate in the couple's negotiation process. The male prevalence is also envisaged under the 'patriarchal' rule. A second heuristic is the sphere-of-interest rule, according to which the partner in whose sphere of interest a decision is located will have greater influence over subsequent behaviour. As long as childbearing tends to lie in the female sphere of interest women will be more influential in the couple's fertility decision-making. A third heuristic is the social-drift rule, according to which the maintenance of the status quo will prevail by favouring the partner who does not want to have children if contraception between births is routine. Neal and Groat (1980) demonstrated that women who perceive their broader environment as being unpredictable develop a life style characterised by social drift and they respond to events like pregnancy as they happen rather than deliberately causing them to happen through an effort of their own. Jansen and Liefbroer (2006) argued that in the Netherlands such a rule controls couples' reproductive choices if neither of the partners has a clear intent to impose her/his own point of view to the other.

In Italy, the literature on the negotiation process of fertility choices within couples is scarce. Recent analysis on the determinants of couple disagreement about childbearing intentions suggests that women in more egalitarian relationships, i.e. those who cohabit and those who work on the labour market, are more likely to express their disagreement if their partner wants a first or a second child (Rosina and Testa 2009; Cavalli 2010). 


\section{Research hypotheses}

Italy is characterised by low financial support to families with children (as several reports by the Organization for Economic Cooperation and Development have repeatedly highlighted) and a lack of adequate policy measures that facilitate the conciliation of work and family life (such as parental leave, child care provision and the access to part-time employment). In such a context childbearing is seen as a potential threat for the achieved standard of living (economics, leisure, etc.) and the lack of agreement between partners may favour the one who does not want to have a child, given that delaying fertility is a normatively acceptable life course strategy, while having a baby has immediate and permanent implications for individuals (Rindfuss et al. 1988). Low societal support for childbearing increases the costs of having an unplanned child and favours partners who plan not to have a child. This evidence led us to formulate a first working hypothesis as follows:

Partners with discordant childbearing plans are closer to partners agreeing on not having a child than to partners agreeing on having a child (Hypothesis 1).

In the traditional Italian society with low gender equity at the individual and societal level, women carry the main responsibility of child care and childrearing activities and therefore couples and the whole society may view decisions on childbearing as fair if the woman's view predominates. We therefore advanced a second working hypothesis as follows:

Fertility decisions lie prevalently in the woman's sphere of interest (Hypothesis 2).

In the theoretical framework proposed by Miller and Pasta (1995) one of the major factors explaining the inconsistency between intended and actual reproductive behaviour is the partner's discrepant intention. A large amount of empirical findings showed that partners' conflicting preferences offer a valid explanation to the divergence between stated plans and subsequent outcomes, which does not imply that people are mistaken about what they want or are unsuccessful in achieving it. Hence, we elaborated a third research hypothesis as follows:

The predictive accuracy of child-timing intentions considerably increases if both partners' views are considered in the measure (Hypothesis $3 a$ ).

Moreover, since women are likely to dominate the couple's negotiation process, women responses reflect the couple's subsequent behaviour more closely than men responses (Hypothesis 3b). 


\section{Data and methodology}

\subsection{Data}

We used data from the Multipurpose Household Survey on "Family and Social Subjects", carried out by the Italian National Statistical Office (Istat) between 2003 and 2007. The survey unit here is the household, so that information on the both members of the couple is available. The follow-up wave includes 10,000 individuals who were randomly drawn from the initial sample of 50,000 respondents interviewed at the initial wave. A comparative analysis between all the couples interviewed in 2003 and those followed up in 2007 did not evidence any significant difference in the distribution of some demographic variables such as: female partner's age, couple's parity, marital status, education and employment status of the man and the woman, and the couple disagreement. The share of couple disagreement is the same in the 2003 sample and the 2007 followup.

The survey was addressed to people aged 18-64 years but questions on fertility intentions were asked only to respondents 18-49 years old. Within this age group, we selected only men and women living in a union at the time of the initial wave, independently on whether they were married or cohabiting. We further restricted the analytic sample to couples in which both partners provided answers to the fertility intentions questions at the initial survey (we registered $4 \%$ of non responses) and at least one of the two provided information about births, adoptions and marital disruption that occurred between the two waves (20032007). If only one of the partners was followed up (this circumstance affected $60 \%$ of the couples interviewed in 2003), we checked for the possibility that she/he experienced a partnership disruption in the inter-survey period. This was the case for $1 \%$ of the respondents re-interviewed in 2007 without their partner. These cases are taken out from the analysis because if a birth occurred in the inter-survey period we could not figure out whether this happened in the framework of the old or a new relationship. Eventually, our analytic sample includes 2356 couples for whom we examined the relationship between the initial intentions and the subsequent reproductive behaviour.

\subsection{Measures}

People re-interviewed in 2007 were asked whether they had a child in the intersurvey period, either their own biological children, affiliated and/or adopted ones. The survey questions were: "From November 2003 up to now have you had any child?" and "From November 2003 up to now have you adopted a child or have you had an affiliated child?" Information on the number of children had and the precise date of each birth as well as on the sex of each newborn were also asked in the questionnaire. 
People interviewed in 2003 had been required to indicate their short-term fertility intentions by answering to the following item: Do you intend to have a child in the next three years? The response options were: definitely not, probably not, probably yes, definitely yes. The circumstance that respondents were reinterviewed after three years makes such measures particularly suitable for the analysis of the predictive accuracy of child-timing intentions.

Exactly the same questions were addressed to both partners, allowing a fully comparative analysis between them. Moreover, all the fertility intentions items were included into the self-administered questionnaires. This circumstance ensures a high degree of independence between the answers of the partners in comparison to other surveys in which both partners may be present at the interview (as for instance in the case of the British Household Panel Survey, see Berrington 2004). We did not find any systematic difference in the responses given by the male and female partners, both men and women used the given response options in the same way to express the strength of their childbearing plans.

Additional questions on fertility intentions were contemplated in the questionnaire, such as, "In the future do you intend to have any child?" and "How many children would you like to have over your life course?"

We focused on partners' responses which go in opposite directions, i.e. to have a child versus not to have a child, independently on whether definitely or probably. However, we did some sensitivity analysis on couples in which partners reported different levels of certainty about having or not having a child, i.e. definitely yes versus probably yes; probably not versus definitely not. The results of this exploratory analysis are only very briefly reported in our article (Section 5.1), more details may be provided by the authors upon request.

\subsection{Methods}

We ran logistic regression models. The response variable has been set equal to 1 if couples had a child in the inter-survey period and 0 otherwise.

The covariates list includes the couple disagreement, as defined by partners' intentions going in opposite directions, as well as several background variables: age, marital status, education, employment status, frequency of attending religious services, women's satisfaction with the gender division of household tasks, geographical area. All the covariates refer to the time of the first interview. The only continuous variable is age which has been centred on the rounded mean values, 38 and 41 years for female and male respondents, respectively. All the other variables are categorical and they have been transformed into suitable dummy variables.

The marital status includes two different categories: married and cohabiting. The latter category refers not only to partners never married but also to couples in which one or both partners was/were already married. 
Education encompasses three main categories: low, medium and high. Low education is related to respondents who had no education or a primary or a lower secondary school certificate. Medium education includes those people with a vocational secondary school diploma or an upper secondary school diploma. The high education group refers to individuals with a university degree (either 3 or 5 years) or postgraduate qualification.

Employment status takes the following categories: employed, unemployed, not active. The unemployed category includes those seeking a job, either their first job or a new one. The inactive category encompasses housewives, students and other non-employed people (conscript, volunteer, disabled). These two categories have been merged into one for the male respondents because of too few cases of non-employed men in the survey data.

The variable referring to the attendance of religious service is not restricted to any specific religion or denomination. The survey question was addressed as follows: How often do you go to the church or to another place of religious worship?

Women's satisfaction with the gender division of household and family duties has been computed by using the female responses to the following item: How much are you satisfied with the gender division of household and family duties between you and your partner? Response options were: very, quite, little, not at all. We assumed women to be unsatisfied if they indicated an answer other than very. A different codification by grouping very and quite in one category and little and not at all in another category did not significantly discriminate the women with respect to their degree of satisfaction with their partner's collaboration in domestic tasks. We describe in Table 2 all the variables used in the multivariate analysis.

We separately examined childless couples and couples who had at least one common child at the time of the first survey, trying to run a more refined stratified analysis whenever possible. We chose a parity-specific approach because the influence of wives and husbands in reproductive decision-making process is strongly affected by the number of previously born children (Beckman et al. 1983), and because dissimilar intentions of the partners may have a different impact on couples at different parities (Miller and Pasta 1995). Moreover, we believe that parity-specific intentions represent more concrete childbearing choices (Bulatao 1981; Morgan 1985) according to the view of a fertilitysequential decision-making process (Namboodiri 1972). 
Table 2:

Distribution of variables used in the multivariate analysis. Values in per cent

\begin{tabular}{|c|c|c|c|c|c|}
\hline & $\begin{array}{c}\text { Both } \\
\text { intend }\end{array}$ & $\begin{array}{c}\text { Only she } \\
\text { intends }\end{array}$ & $\begin{array}{l}\text { Only he } \\
\text { intends }\end{array}$ & $\begin{array}{l}\text { Neither } \\
\text { intends }\end{array}$ & $\begin{array}{c}\text { No. of } \\
\text { cases }\end{array}$ \\
\hline Married & 20 & 3 & 4 & 73 & 2261 \\
\hline Cohabiting & 48 & 4 & 6 & 41 & 93 \\
\hline Woman with low education & 15 & 3 & 3 & 80 & 874 \\
\hline Woman with medium education & 24 & 3 & 4 & 70 & 1170 \\
\hline Woman with high education & 31 & 4 & 6 & 59 & 310 \\
\hline Man with low education & 19 & 2 & 4 & 75 & 1012 \\
\hline Man with medium education & 22 & 3 & 4 & 71 & 1049 \\
\hline Man with high education & 28 & 3 & 4 & 65 & 293 \\
\hline Woman employed & 23 & 3 & 5 & 69 & 1186 \\
\hline Woman not employed & 22 & 3 & 5 & 70 & 252 \\
\hline Woman enrolled in education & 19 & 3 & 2 & 76 & 916 \\
\hline Man employed & 21 & 3 & 3 & 73 & 1583 \\
\hline Man not employed or inactive & 23 & 3 & 5 & 69 & 771 \\
\hline \multicolumn{6}{|c|}{ Woman's attendance of a religious service } \\
\hline Less than once a month & 19 & 3 & 3 & 74 & 862 \\
\hline At least once a month & 23 & 2 & 4 & 71 & 1492 \\
\hline \multicolumn{6}{|c|}{ Man's attendance of a religious service } \\
\hline Less than once a month & 20 & 3 & 4 & 73 & 602 \\
\hline At least once a month & 22 & 3 & 4 & 72 & 1752 \\
\hline \multicolumn{6}{|c|}{ Woman's satisfaction with gender division of family duties } \\
\hline Not satisfied & 20 & 3 & 4 & 74 & 1867 \\
\hline Satisfied & 28 & 3 & 3 & 66 & 487 \\
\hline Woman's age: up to 38 & 34 & 4 & 6 & 56 & 1277 \\
\hline Woman's age: above 38 & 6 & 1 & 1 & 92 & 1077 \\
\hline Man's age: up to 41 & 35 & 4 & 5 & 55 & 1262 \\
\hline Man's age: above 41 & 5 & 1 & 2 & 91 & 1092 \\
\hline Northern and central Italy & 22 & 3 & 4 & 71 & 1139 \\
\hline Southern Italy & 20 & 2 & 4 & 73 & 1215 \\
\hline No. of cases & 504 & 65 & 90 & 1695 & 2354 \\
\hline
\end{tabular}

\section{Results}

\subsection{Descriptive analysis}

We found that the majority of childless partners agreed to have a child at the time of the first wave $(67 \%)$ while only $25 \%$ of them agreed on not having any baby in the short-term period. Moreover, the amount of disagreement between partners about child-timing intentions was quite low (8\%) and equally divided between the cases in which only she intended to have a child (4\%) and only he intended to have one (4\%) (Table 3 ). We got a similar picture when examining only partners who had at least one common child at the beginning of the longitudinal study. The main difference to their childless counterparts was that the majority agreed on not 
planning an additional child (79\%) while only $14 \%$ reported a concordant intention to have a child in the next three years (Table 3).

Slightly more than $50 \%$ of the couples who agreed on having a child in the short-term period also had one in the inter-survey period, 53\% and 52\% among childless couples and parents, respectively. The same percentages were very low and equal to $4 \%$ and $3 \%$ in the case of couples where neither of the partners intended to have a child in the first place, suggesting that the level of unintended pregnancies was quite low in the period between the surveys.

The reproductive behaviour of couples in disagreement at the time of the first wave depended on whether only she or only he wanted a child and varied with the actual couple's parity. Couples in which only women wanted a child more often actually had one than couples in which only he reported an intention to have a child $(50 \%$ versus $33 \%$ among childless couples, and $25 \%$ versus $19 \%$ among couples with children) (Table 3 ).

Table 3:

Intentions to have a child in the next three years and subsequent outcomes

\begin{tabular}{lrrr|rrr}
\hline $\begin{array}{l}\text { Couples' intention to } \\
\text { have a child in the next } \\
\text { three years }\end{array}$ & \multicolumn{2}{c|}{$\begin{array}{c}\text { Percentage } \\
(\mathbf{2 0 0 3 )}\end{array}$} & & \multicolumn{2}{c}{$\begin{array}{c}\text { Percentage had a child in the } \\
\text { inter-survey period } \\
\text { (2003-2007) }\end{array}$} \\
\hline & Childless & Parents & All & Childless & Parents & All \\
\hline Both partners intend & 67 & 14 & 21 & 53 & 52 & 53 \\
She intends, he does not & 4 & 3 & 3 & 50 & 25 & 29 \\
He intends, she does not & 4 & 4 & 4 & 33 & 19 & 21 \\
Neither partner intends & 25 & 79 & 72 & 4 & 3 & 3 \\
Total & 100 & 100 & 100 & 40 & 11 & 15 \\
\hline
\end{tabular}

As shown in Figure 1, the level of couples' fertility declined with the age of the female partner, irrespective of whether there was initial agreement about reproductive intentions between partners or not. In case of a conflict women had a stronger influence in the reconciliation of the opposing preferences. If only the woman wanted a child couples experienced childbearing outcomes in between that of couples agreeing on having a child and that of couples agreeing on not having one. By contrast, couples in which only the man wanted a child had the same fertility level as couples in which neither partner planned a birth if the woman was 35 years old or older (Figure 1).

As outlined in Figure 2, the couple fertility rates did not vary with the actual couple's parity if both partners had expressed the same child-timing intentions at the time of the first survey. However, the reproductive outcomes steeply decreased by parity if the partners had not initially reported consistent plans: if they were childless, they had a birth almost as often as partners who both wanted a child, if they shared already one child, they had outcomes in between those of couples agreeing on having or not having a child, and if they had two or more 
children they showed a similar behaviour as couples in which both partners did not want a child (Figure 2).

By examining couple disagreement as defined by the differences in the level of certainty between the partners' responses we came up with the same findings as outlined above, except that women's predominance was no longer remarkable (results are available on request).

As shown in Figures 3 and 4, we found that the predictive accuracy of fertility intentions strongly improved once we disentangled the women's and men's childbearing intentions into those accompanied by a partner's agreement and those combined with a partner's disagreement. The childbearing rates of women who had reported the intention to have a child in the short run at the time of the initial survey tended to increase if they met their partner's agreement and to decrease if they did not meet it (Figure 3). These trends developed at a pace gradually increasing by parity. At parity zero and one, the childbearing outcomes of all women and those of women with and without partner's agreement were very close to each other, but at parity two and above the childbearing rates were 12 percentage points higher if the man agreed on having a child and 23 percentage points lower if he had a different view (Figure 3). By examining the male childbearing rates, we got similar findings. The only substantial difference concerns the lower first-birth risks of men with a partner disagreeing on having a child: these men had childbearing risks 19 percentage points lower than those of all the men (Figure 4).

Figure 1:

Share of couples having a child in 2003-2007 by woman's age

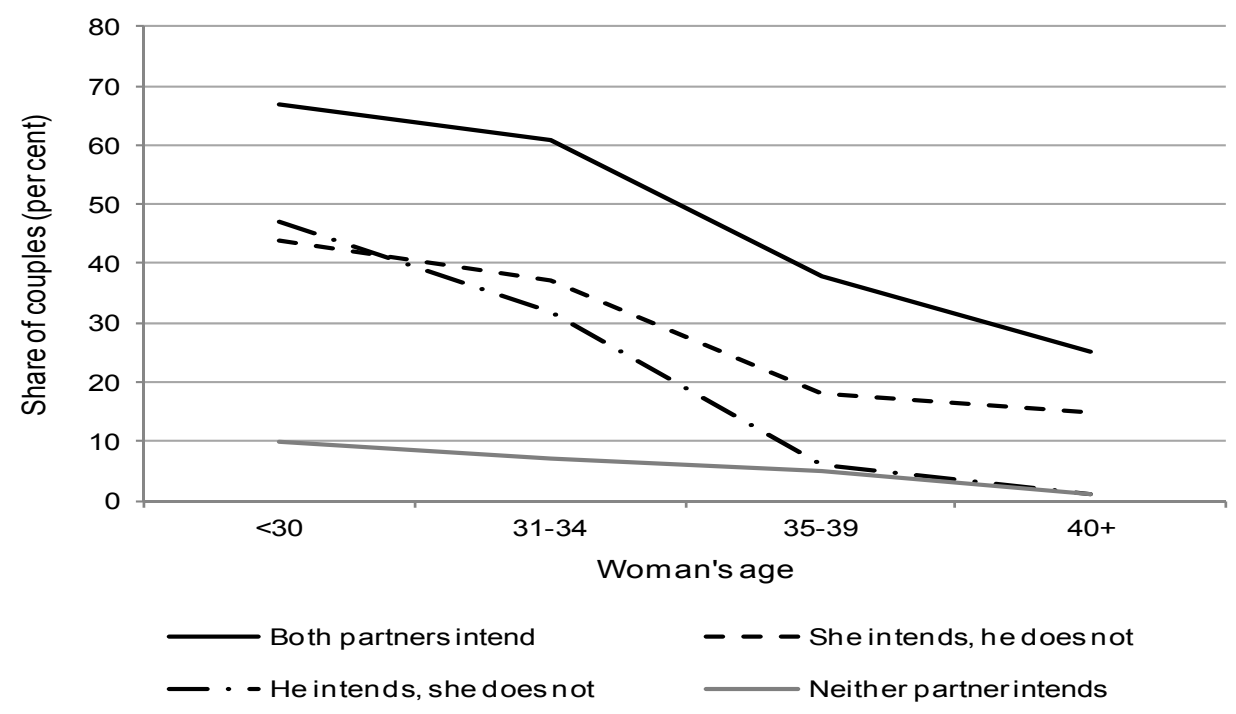


Figure 2:

Share of couples having a child in 2003-2007 by couple's parity
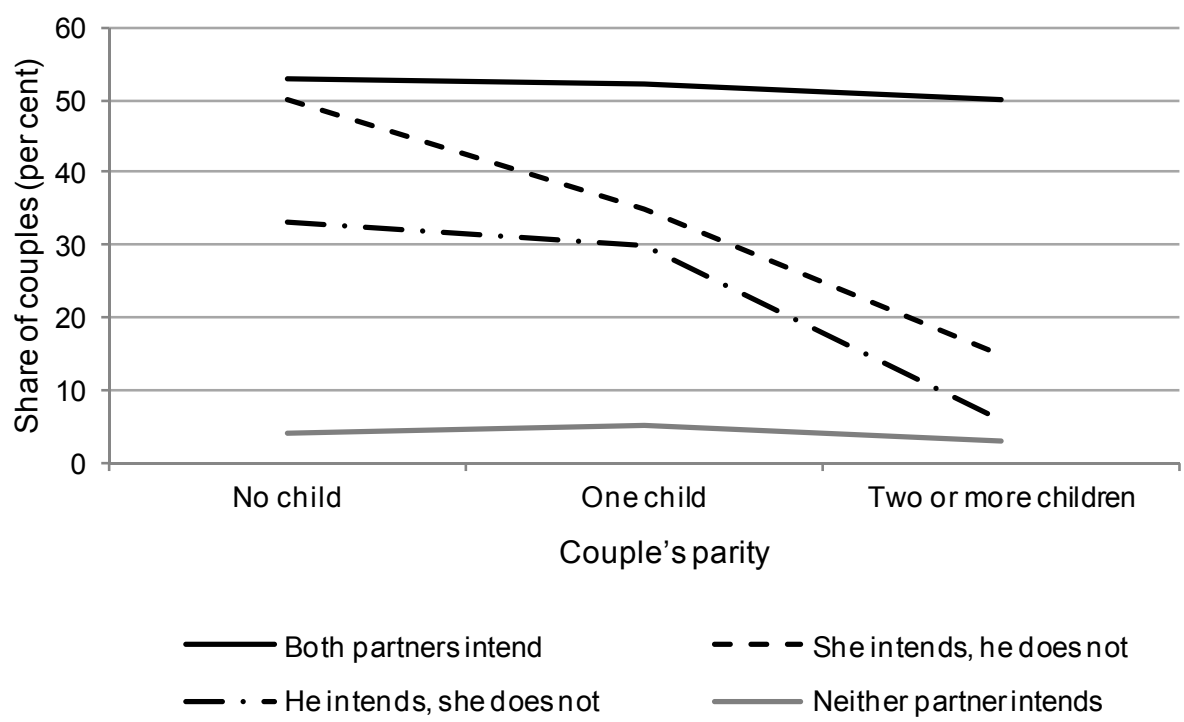

Figure 3:

Share of women having a child in 2003-2007 by couple's parity. All women who intend to have a child and only those with or without their partner's agreement

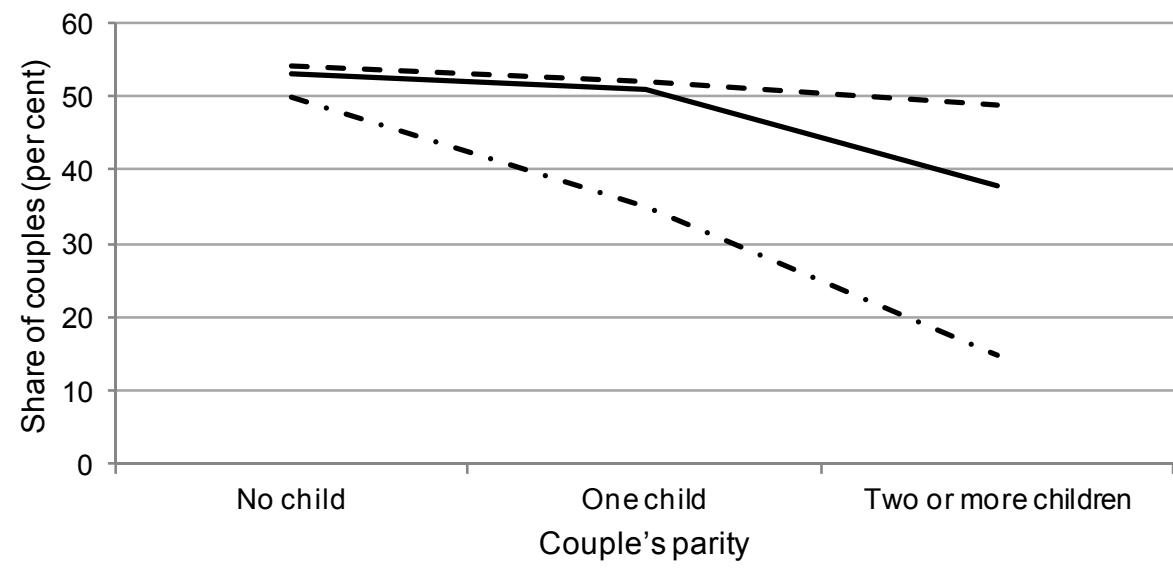

_ All women who intend to have a child

- - with a partner's ag reement

- - without a partner's agreement 
Figure 4:

Share of men having a child in 2003-2007 by couple's parity. All men who intend to have a child and only those with or without their partner's agreement

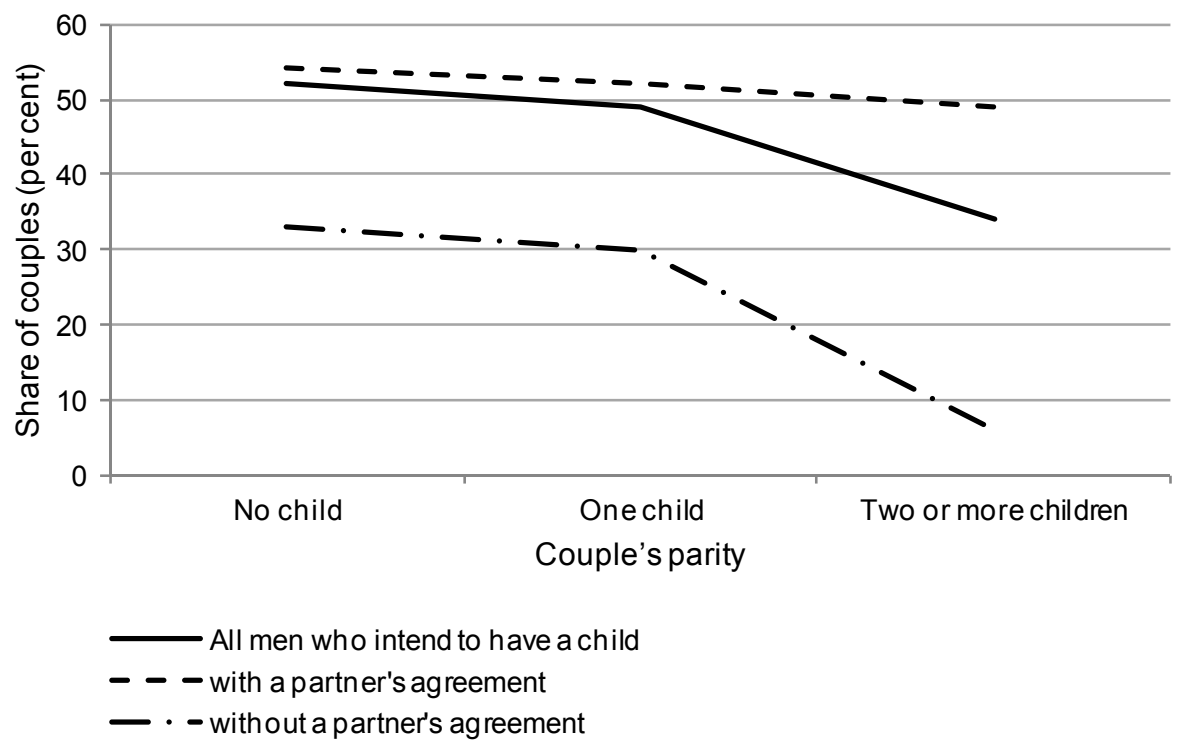

\subsection{Multivariate analysis}

By running a series of logistic regression models predicting the likelihood of a birth we proved that intentions are powerful predictors. Net of other covariates, if both partners agreed to have a child they were, at parities zero, one and two or above respectively, 16.7, 6.7 and 25 times (in terms of odds ratios) more likely to have a child than couples where both agreed not to have a child. If one partner intended to have a child but the other did not, then the likelihood of a birth was substantially reduced. At all three parities, the woman's intent had a larger effect than the man's, and this difference was greatest at parity zero and weakest at parity one. The lack of agreement between partners was a significant deterrent of a couple's subsequent childbearing outcome. Indeed, conflicting partners faced lower risks of having a child than partners who initially were in agreement about their childbearing plans. The negative effect of partners' diverging views on subsequent births increased with their parity (Table 4).

Moreover, in the event of a conflict, the women's childbearing plans exerted a greater impact on subsequent outcomes than the men's intentions, once other variables were controlled for. The inhibiting effect of disagreement on childbearing was stronger for partnerships in which the woman did not want to have a child while the man wanted one (odds ratios on having a child are equal to 6,3 and 2 for parity zero, one, and two or above, respectively) than for the unions 
in which the man did not want a child but the woman did (odds ratios on having a child are equal to 15,3 and 5 for parity zero, one, and two or above, respectively) (Table 4).

Among other relevant predictors of childbearing we found that a cohabiting status of the partners decreased the chance to have a first child while the woman's dissatisfaction with the gender division of household tasks reduced the likelihood to have a third or a higher birth order child. The estimates of the models confirmed the negative effect of woman's age on couple reproduction that was already accounted for in the descriptive analysis.

We estimated all possible interactions between the partner's conflicting intentions and the full set of covariates considered in the model. None of the interactions were statistically significant which is why none were retained in the models. We could be tempted to conclude that the effect of a couple's conflicting preferences on childbearing behaviour does not vary by the socio-demographic variables included in the models but we should be cautious in making such an assumption because the limited sample size reduces the possibility of identifying any statistically significant interaction effects.

Examining the predictive power of fertility intentions by taking either the woman's (Table 5a) or the man's perspective (Table 5b) and comparing models with and without partner's agreement (Models II and I, respectively), we found that the inclusion of the partner's agreement significantly improved the model fit; the only exception was childless women. For men the improvement in fit was greater with the women's intentions taken into account than the improvement in fit for women taking into accounts the men's intentions.

The odds ratios of both partners agreeing on having a child were always higher than the odds rations of either only the woman or only the man wanting a child (Model II in Table 5a and 5b).

As we expected, the event of a conflict between partners at the time of the first survey takes an important role in explaining the inconsistencies between stated fertility plans and subsequent outcomes. However, differences by parity and type of inconsistency (whether intentions over- or underestimate the subsequent reproduction outcome) are remarkable.

The share of respondents whose intentions overestimated their subsequent childbearing outcome decreased by parity: the percentages were $33 \%$ and $34 \%$ of childless, 20 and $21 \%$ of those with one child and $4 \%$ and $5 \%$ of those with two or more children, for women and men, respectively. By contrast, consistency between intentions and outcomes increased by parity: it was $64 \%$ and $62 \%$ at parity zero, $77 \%$ and $75 \%$ at parity one and $93 \%$ and $92 \%$ at parity two or above, again for women and men, respectively. The share of respondents whose intentions underestimated their subsequent childbearing was low, ranging between 2 and $5 \%$ (first panel of Table 6 ). 
Table 4:

Odds ratios on having a child in the inter-survey period (2003-2007)

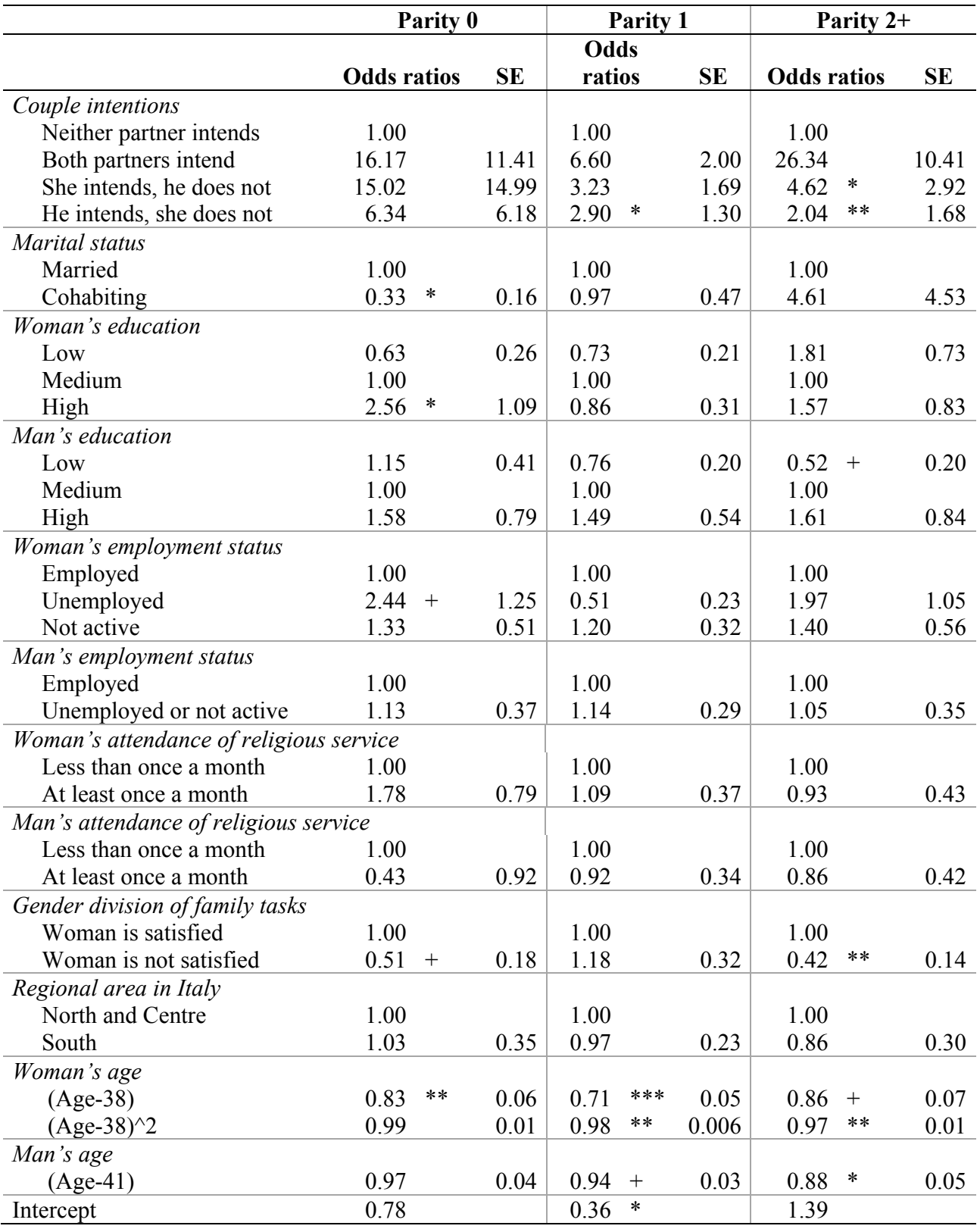

Note: ${ }^{+} \mathrm{p}<0.1 ;{ }^{*} \mathrm{p}<0.05 ; * * \mathrm{p}<0.01 ; * * * \mathrm{p}<0.001$ 
Table 5a:

Odds ratios for having a child in the inter-survey period from the woman's perspective

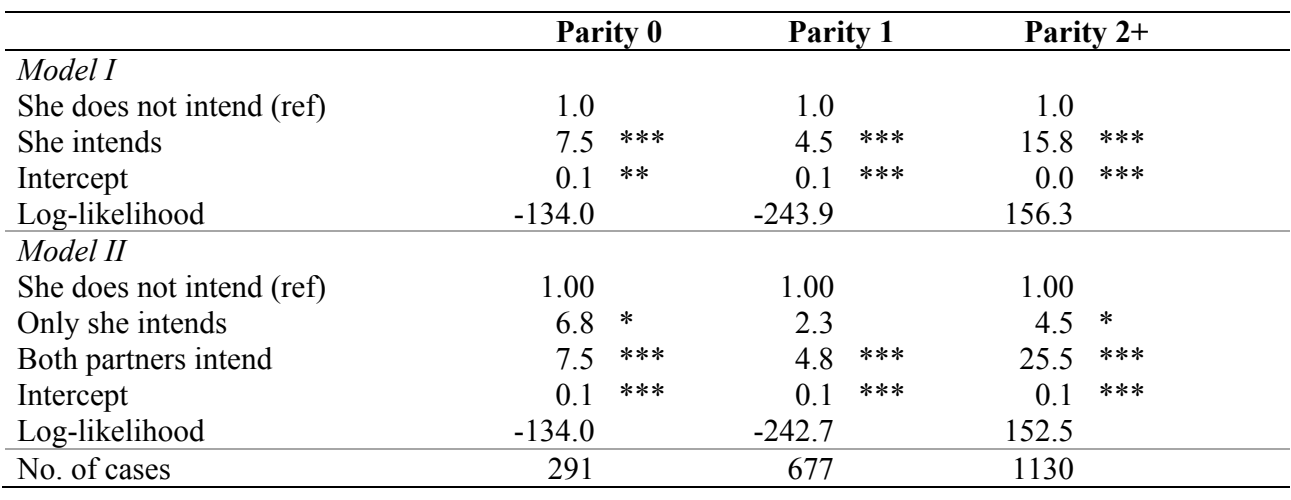

Note: $* \mathrm{p}<0.05 ; * * \mathrm{p}<0.01 ; * * * \mathrm{p}<0.001$

Estimates net of all the variables considered in Table 3

The partner's disagreement was relevant in explaining the underestimation of fertility at parity zero or one: $57 \%$ and $67 \%$ of childless women and men and 50 and $33 \%$ of women and men respectively with one child who had a child in the inter-survey period without an explicit intent to do so met a partner's discrepant opinion (second panel of Table 6). The partner's disagreement was important in explaining the overestimation of fertility at parities two and above: $46 \%$ and $54 \%$ of women and men, respectively, with two or more children who planned, but did not manage to actually have, an additional one faced their partner's disagreement (second panel of Table 6).

Table 5b:

Odds ratios for having a child in the inter-survey period from the man's perspective

\begin{tabular}{lrrr}
\hline & Parity 0 & Parity 1 & Parity 2+ \\
\hline Model I & & & \\
He does not intend (ref) & 1.0 & 1.0 & 1.0 \\
He intends & $5.4 * * *$ & $4.5 * * *$ & $13.1 * * *$ \\
Intercept & $0.1 * *$ & $0.1 * * *$ & $0.1 * * *$ \\
Log-likelihood & -137.2 & -244.7 & -160.6 \\
\hline Model II & & & \\
He does not intend (ref) & 1.0 & 1.0 & 1.0 \\
Only he intends & 2.1 & 2.2 & 1.9 \\
Both partners intend & $5.7 * * *$ & $5.1 * * *$ & $23.6 * * *$ \\
Intercept & $0.1 * *$ & $0.1 * * *$ & $0.1 * * *$ \\
Log-likelihood & -136.2 & -242.4 & -154.6 \\
No. of cases & 291 & 677 & 1130 \\
\hline
\end{tabular}

Note: $* \mathrm{p}<0.05 ; * * \mathrm{p}<0.01 ; * * * \mathrm{p}<0.001$

Estimates net of all the variables considered in Table 4 
A partner's diverging view was very seldom observed if the intentions stated in 2003 consistently reflected the births observed in 2007 . The percentage values varied by parity and respondent's sex, but they were always below $10 \%$ (second panel of Table 6).

Table 6:

Correspondence between fertility intentions and subsequent outcomes by gender and parity

\begin{tabular}{lccc|ccc}
\hline & \multicolumn{3}{c|}{ Percentage distribution } & \multicolumn{3}{c}{$\begin{array}{c}\text { Percentage facing a partner's } \\
\text { disagreement }\end{array}$} \\
\hline & Parity 0 & Parity 1 & Parity 2+ & Parity 0 & Parity 1 & Parity 2+ \\
\hline Women & & & & & & \\
Over-estimation & 33 & 20 & 4 & 6 & 13 & 46 \\
Consistency & 64 & 77 & 93 & 6 & 8 & 3 \\
Under-estimation & 2 & 5 & 3 & 57 & 50 & 7 \\
Total & 100 & 100 & 100 & 8 & 10 & 5 \\
\hline Men & & & & & & \\
Over-estimation & 34 & 21 & 5 & 8 & 21 & 54 \\
Consistency & 62 & 75 & 92 & 5 & 6 & 2 \\
Under-estimation & 3 & 4 & 2 & 67 & 33 & 13 \\
Total & 100 & 100 & 100 & 8 & 10 & 5 \\
\hline
\end{tabular}

Note: Intentions can over-estimate, consistently estimate or under-estimate subsequent fertility. Over-estimation refers to the cases in which respondents intended to have a child but did not have one in the subsequent period. Consistency refers to the cases in which respondents either did not intend to have a child and indeed did not have one or intended to have a child and indeed had one in the subsequent period. Under-estimation refers to the cases in which respondents did not intend to have a child but had one in the subsequent period.

\section{Summary and discussion}

In this analysis we examined short-term childbearing intentions and subsequent reproductive behaviour of Italian couples. We aimed at getting insights on the role of couple interactions in reproductive decision-making. This concern is generating a growing amount of interest in academic research. However, it is still under-investigated because it requires high-quality data which are not easy to collect. Our study design was particularly suitable for its aim because it reflected a genuine couple approach in a longitudinal perspective.

By focusing our attention on disagreeing couples, we advanced the hypothesis that the normative context and the contraceptive regime prevalent in Italy favour, in the case of a conflict, the partner who does not want to have a(nother) child. We also supposed that in the Italian traditional gender setting fertility decisions are predominantly located in the woman's domain. Moreover, we expected a great improvement in the predictive accuracy of fertility intentions when the views of both partners are considered.

Our initial hypotheses could be only partially confirmed. First, we noted that a divergence between the partners' intentions does not necessarily hinder a 
subsequent birth. Childless couples who did not initially agree on their childbearing plans experienced a birth almost as often as couples who previously agreed on having a child. Only if partners were already parents did a lack of agreement actually inhibit a subsequent birth: couples who already had one child showed a middle fertility outcome while partners with two or more children faced a double-veto model, i.e. they had similar birth risks as couples who agreed not to have a child. The existence of a double-veto model is supported only at high parities. The couples included in our sample (married or in a stable cohabitation since at least three years) may be particularly exposed to a certain pressure to become a parent, given that Italy is still a country where childlessness is not very widespread at a normative level (Testa 2006).

Second, we found evidence that women have a stronger influence on childbearing decisions than men. However, this sphere-of-influence rule tends to be abandoned in favour of a golden-mean rule by couples who already had two children. Since the birth of a child is an event with more consequences for women than for men, men might think that it is only fair to leave the final choice on the timing of childbearing to their partner, a finding underlined also by a recent qualitative analysis conducted in Austria (Rille-Pfeiffer 2009).

Third, we pointed out that the predictive accuracy of intentions is notably higher once we disentangle the individuals' fertility plans into those births planned by both and by only one of the partners.

We could support the assumption that models based on both partners' fertility intentions are superior to those based on only one partner's intentions (Fried and Udry 1979; Fried et al. 1980; Morgan 1985) and that models including only the women's intentions are likely to be mis-specified (Corijn et al. 1996). Since women tend to prevail in the couple negotiation process, we share the view that models based on female child-timing intentions should be preferred over models based on male child-timing intentions - if the choice between one of the two partners has to be made (Fried et al. 1980; Morgan 1985).

On the whole, we observed a relatively low level of disagreement between partners irrespective of whether at the time of the first survey they had been childless or already parents.

We interpreted this evidence as a sign that couples come to some understanding about procreation (Fisher 2000). We could also think about an assortative mating process which pushes people to get together with partners who share the same fertility preferences. An interesting research question which lies beyond the scope of our article could concern the degree of homogeneity between partners' fertility preferences produced by the assortative mating.

We should also mention that we have no information on couples' proceptive or contraceptive measures and our assessment of the consistency level between intentions and behaviour is exclusively based on the final outcome of that behaviour, i.e. the birth. Knowing more on the use of contraception would also tell us whether women have a predominant role in this sphere. 
The limited degree of disagreement detected in our study might also be related to another important caveat of our data which has to do with measurement issues. Reported child-timing intentions might reflect the resolution of a negotiation process between partners, as the theory on fertility decision-making (Ajzen 1991; Miller 1994) and some empirical findings (Barret and Wellings 2002) would suggest. If this is true, partners' concordant responses do not exclude the presence of disagreement, or alternatively, partners' discrepant reports might happen by chance (because only one of the two respondents incorporated the partner's view in their answer). Although this is a general challenge in the analysis of couple data (Becker 1996), we suggest that intentions may not be the most suitable element in the dynamic of couple interaction and perhaps we should look at the earlier stages of the fertility decision-making sequence, i.e. desires and motivations, to follow the partners' negotiation process more deeply.

\section{Conclusion}

The analysis of the Italian couple data reveals that men are important actors in fertility decision-making, especially after the birth of a first child. Hence, policymakers willing to develop efficient child-friendly policies should target any interventions not only at women but also at men.

The empirical findings strongly support the importance of gathering data on childbearing intentions from both partners and also suggest to consider additional items in the survey design which would enable the scholars to disentangle whether the stated individual reports reflect a joint decision (and the extent to which they do so), or only the respondent's personal point of view. This approach has been adopted in a survey conducted in the USA in the 1970s (Morgan 1985).

A genuine couple approach increases the correspondence between intended and actual childbearing behaviour and improves our understanding of reproductive decision-making but it does not allow us to consider fertility intention a suitable measure for forecasting fertility. According to our results, only slightly more than $50 \%$ of the couples agreeing on having a child within the next three years have actually had one in the 4-year follow-up period.

\section{Acknowledgements}

We would like to thank Paola Di Giulio and the participants of the Repro Conference held in Vienna on 2-3 December 2010 for their useful comments. 


\section{References}

Ajzen, I. 1991. The theory of planned behavior. Organizational Behavior and Human Decision Processes 50: 179-211.

Barret, G. and K. Wellings 2002. What is a "planned" pregnancy? Empirical data from a British study. Social Science \& Medicine 55: 545-557.

Beckman, L.J. 1983. Communication, power, and the influence of social network in couple decisions on fertility. In Determinants of fertility in developing countries, ed. R.A.Bulatao and R.D. Lee, Vol.2: 415-443. New York: Academic Press.

Beckman, L., R. Aizenberg, A.B.Forsythe and T. Day 1983. A theoretical analysis of antecedents of young couples' fertility decisions and outcomes. Demography 20(4): 519-533.

Beckman, L.J. 1984. Husbands' and wives' relative influence on fertility decisions and outcomes. Population and Environment: Behavioral and Social Issues 7: 182-197.

Becker, S. 1996. Couples and reproductive health: a review of couple studies. Studies in Family Planning 27(6): 291-306.

Berrington, A. 2004. Perpetual postponers? Women's, men's and couple's fertilità intentions and subsequent fertility behaviour. Population Trends 117: 9-19.

Bulatao, R.A. 1981. Values and disvalues of children in successive childbearing decisions. Demography 18(1): 1-25.

Cavalli, L. 2010. Fertility intention for a second child within the Italian couples: a bargaining process approach. Doctoral Thesis. Milan: Università Cattolica del Sacro Cuore.

Coombs, L.C. and M.C. Chang 1981. Do husbands and wives agree? Fertility attitudes and later behavior. Population and Environment 4(2): 109-127.

Corijn, M., A.C. Liefbroer and J. De Jong Gierveld 1996. It takes two to tango, doesn't it? The influence of couple characteristics on the timing of the birth of the first child. Journal of Marriage and the Family 58: 117-126.

Davidson, A.R. and L.R. Beach. 1981. Error patterns in the prediction of fertility behaviour. Journal of Applied Social Psychology 11: 475-488.

Del Boca, D., S. Pasqua and C. Pronzato 2004. Why are fertility and women's employment rates so low in Italy? Lessons from France and the U.K. IZA Discussion Papers 1274.

Fisher, K. 2000. Uncertain aims and negotiation: birth control practices in Britain, 19251950. Population and Development Review 26(2): 295-317.

Freedman, R., D.S. Freedman and A.D. Thornton 1980. Changes in fertility expectations and preferences between 1962 and 1977: relation to final parity. Demography, 17(4): 365-378.

Fried, E.S., S.L. Hofferth and J.R. Udry 1980. Parity-specific and two-sex utility models of reproductive intentions. Demography 17(1): 1-11.

Fried, E.S., and J.R. Udry 1979. Wives' and Husbands' expected costs and benefits of childbearing predictors of pregnancy. Social Biology 26: 256-274.

Jansen, M., and A.C. Liefbroer, 2006. Couple's attitudes, childbirth, and the division of labor. Journal of Family Issues 27(11): 1487-1511.

Lee, R. 1980. Aiming at moving target: period fertility and changing reproductive goals. Population Studies 34(2): 205-226.

Miller, W.B. 1994. Childbearing motivations, desires, and intentions: a theoretical framework. Genetic, Social, and General Psychology Monographs 120(2): 223-258. 
Miller, W. B. and D. J. Pasta 1995. Behavioural intentions: which ones predict fertility behaviour in married couples? Journal of Applied Social Psychology 25: 530-555.

Miller, W.B., and D.J. Pasta 1996. Couple disagreement: effects on formation and implementation of fertility decisions. Personal Relationships 3: 307-336.

Miller, W.B., L.J. Severy, and D.J. Pasta 2004. A framework for modeling fertility motivation in couples. Population Studies 58(2): 193-205.

Morgan, S.P. 1985. Individual and couple intentions for more children: a research note. Demography 22(1): 125-132

Morgan, S.P. 2001. Should fertility intentions inform fertility forecast? In Proceedings of U.S. Census Bureau Conference: the direction of fertility in the United States, ed. G.K. Spencer. Alexandria, VA: Council of Professional Associations of Federal Statistics.

Namboodiri, N.K. 1972. Observations on the economic framework for fertility analysis. Population Studies 26(2): 185-206.

Neal, A.G., and H.T. Groat. 1980. Fertility decision making, unintended births, and the social drift hypothesis: a longitudinal study. Population and Environment 3(3-4): 221-236.

Pinnelli, A. 1995. Women's condition, low fertility, and emerging union patterns in Europe. In Gender and family change in industrialized societies, ed. K.O. Mason and A.M. Jensen. Oxford: Clarendon Press.

Rille-Pfeiffer, C. 2009. Kinder - jetzt, später oder nie? Generatives Verhalten und Kinderwunsch in Österreich, Schweden und Spanien. Schriftenreihe des Österreichischen Instituts für Familienforschung (ÖIF) 21. Vienna: Budrich UniPress.

Rindfuss, R.R., P.S. Morgan, and G. Swicegood 1988. First births in America: changes in the timing of parenthood. Berkeley and Los Angeles: University of California Press.

Ryder, N. 1973. A critique of the National Fertility Study. Demography 10(4): 495-506.

Rosina, A. and M.R. Testa 2009. Couples' first child intentions and disagreement: an analysis of the Italian case. European Journal of Population 25(4): 487-502.

Saraceno, C. 1994. The ambivalent familism of Italian welfare state. Social Politics 1.

Testa, M.R. 2006. Childbearing preferences and family issues in Europe. Special Eurobarometer 253/Wave 65.1 - TNS Opinion \& Social, European Commission.

Thomson, E., E. McDonald, and L.L. Bumpass 1990. Fertility desires and fertility: hers, his and theirs. Demography 27(4): 579-588.

Thomson, E. 1997. Couple childbearing desires, intentions and births. Demography 34(3): 343-354.

Thomson, E. and J. Hoem 1998. Couple childbearing plans and births in Sweden. Demography 35(3): 315-322.

Townes, B.D., L.R. Beach, F.L. Campbell and R.L. Wood 1980. Family building: a social psychological study of fertility decisions. Population and Environment 3(3-4): 210-220.

Voas, D. 2003. Conflicting preferences: a reason fertility tends to be too high or too low. Population and Development Review 29(4): 627-646. 